\title{
Prescribing of asthma medication in primary care for children aged under 10
}

\author{
*Siebrig Schokkera, Feikje Groenhof ${ }^{a}$, Willem Jan van der Veena, Thys van der Molen \\ a Department of General Practice, University Medical Center Groningen, University of Groningen, Netherlands
}

Originally received 17th June 2008; resubmitted 10th October 2008; revised version received 28th November 2008;

further revision 27th March 2009; accepted 11th April 2009; online 6th August 2009

\begin{abstract}
Objective: To evaluate prescriptions of asthma medication for children in primary care.

Methods: Data on prescriptions of asthma medication for children aged 0-9 years were collected from a general practice-based network in the north eastern part of the Netherlands. Prevalence, incidence, indications, continuation beyond the age of 6 years, and predictors of continuation, were determined.

Results: Prevalence of prescriptions was about 80 per 1000 person years. An asthma diagnosis was registered in $40 \%$ of the children with a first prescription and in $70 \%$ of the children with six or more prescriptions. Discontinuation of asthma medication was between 60 and $90 \%$. Continuation was more likely in children with a first prescription at age 2 or 3 as compared to children starting treatment at age $\leq 1$ year. Children with prescriptions for $\beta_{2}$-agonists and inhaled corticosteroids were more likely to continue treatment than children with $\beta_{2}$-agonist monotherapy prescriptions.

Conclusion: Continuation of asthma medication in children is low. Age at first prescription and the type of asthma medication are predictors of continuation of asthma medication from preschool into school-age.

(C) 2010 Primary Care Respiratory Society UK. All rights reserved.

S Schokker et al. Prim Care Resp J 2010; 19(1): 28-34.

doi:10.4104/pcrj.2009.00039
\end{abstract}

Keywords asthma, paediatrics, primary care, medications, prescriptions

\section{Introduction}

Respiratory symptoms such as cough, wheeze, or shortness of breath are common in young children; almost half of all children have experienced respiratory symptoms by the age of six years. ${ }^{1}$ These respiratory symptoms are part of a heterogeneous condition, ranging from viral-associated wheeze to atopic asthma. In clinical practice, these phenotypes cannot be differentiated until children are aged five or six years old.

In primary care, respiratory symptoms in young children are a common reason for consultation. Primary Care Physicians (PCPs) are often faced with children with nonspecific symptoms which may, or may not, be suggestive of asthma. PCPs have to sort out the possible differential diagnoses during consultations and are responsible for making clinical decisions. The diagnostic difficulty in young children with respiratory symptoms has been illustrated recently in this journal by Bush. ${ }^{2}$ Several predictive indicators include the frequency of wheezing episodes, concurrent eczema, allergic rhinitis, recurrent otitis media, a family history of asthma or eczema, as well as eosiniphilia and sensitisation to inhalant allergens. ${ }^{3.5}$ The predictive value of these indicators, however, is low, and therefore the diagnosis of asthma in children is still a challenge for clinicians. Consequently, it is unclear which children with respiratory symptoms should be prescribed asthma medication, thus resulting in possible under- or over-treatment.

Asthma medication is often prescribed in children. As recommended in guidelines, short-acting $\beta_{2}$-agonists and inhaled corticosteroids (ICS) are the cornerstone of treatment

\footnotetext{
* Corresponding author: Siebrig Schokker, Department of General Practice, University Medical Center Groningen, University of Groningen, A. Deusinglaan 1 Groningen, 9713 AV Netherlands. Tel: +31503632951 Fax: +31503632964 E-mail: s.schokker@med.umcg.nl
} 
in childhood asthma. ${ }^{6-8}$ Although a disease-modifying effect of ICS has not so far been demonstrated, ${ }^{9-11}$ the beneficial effects of ICS on symptoms, exacerbations and lung function have been found in studies which included stringentlyselected groups of children.9,12,13 On the other hand, studies including a more heterogeneous population, such as children from primary care, showed no beneficial effect of ICS. ${ }^{14,15}$

The key issue seems to be diagnostic uncertainty, and the resulting uncertainty regarding the optimal treatment of these children. Since time is the only factor which can teach us more about the outcome of respiratory symptoms in early childhood, studies using longitudinal data offer a unique opportunity to explore the diagnostic and therapeutic issues in children with asthma or asthma-like symptoms.

The aim of this study, therefore, was to assess asthma medication prescriptions for children in primary care. The prevalence and incidence and the indications for these prescriptions were evaluated. In addition, continuation of the prescriptions from preschool-age into school-age was determined. Finally, predictors of continuation, such as age at first prescription, indication, sex, presence of eczema, type of asthma medication, and use of antibiotics, were explored.

\section{Methods}

Data were obtained from the Registration Network Groningen (RNG). This general practice-based research network was established in 1989 and consists, at present, of three group practices based in the north-eastern part of the Netherlands. Participating general practitioners (GPS) register all care delivered to their patients. About 30,000 regular patients (approximately 3,600 aged 0-9 years, 2,400 aged 1017 years, and 24,000 aged 18 years and older) are registered yearly. All consultations, with the reasons for the encounter as well as the diagnosis and the prescriptions, are registered. Morbidity data are electronically recorded using the International Classification of Primary Care (ICPC) ${ }^{16}$ and each prescribed medication is provided with an ICPC-based indication. The prescriptions are automatically classified with an Anatomical Therapeutical Chemical (ATC) code. ${ }^{17}$ In this study, asthma medication was defined as the ATC-group R03 ('drugs for obstructive airway diseases'). Specific asthma medications used by our study population included: $\beta_{2}$ agonists (R03AC and R03CC); inhaled corticosteroids (R03BA); and adrenergics and other drugs for obstructive airway diseases (R03AK). Children with prescriptions of asthma medication were divided into three different groups: 1) children prescribed $\beta_{2}$-agonists only $\left(\beta_{2}\right.$-agonist monotherapy); 2) children prescribed inhaled corticosteroids only (ICS monotherapy); or 3 ) children prescribed $\beta_{2}$-agonist as well as ICS, either in combination or as two separate drugs, irrespective of consecutive or concurrent use during the study period ( $\beta_{2}$-agonist and ICS therapy). Furthermore, we used a diagnosis of asthma as per the PCP (doctor-diagnosed asthma), registered in the database as ICPC-code R96 (asthma).

\section{Data analysis}

Three observational data analysis designs were employed. First, a cross-sectional design was used to describe the prescribing practice of PCPs with respect to asthma medication for children aged 0-9 years. Secondly, a longitudinal design was used to estimate the probabilities of continuation of asthma medication for children starting this medication at different ages. Finally, a retrospective casecontrol design was employed to analyse factors which might be predictive of continuation of asthma medication prescriptions beyond 6 years of age.

\section{- Cross-sectional analysis}

To obtain frequency measures of prescribing asthma medication a population of children was selected, including each child under the age of 10 during the study period 19982005. For calculating prevalence and incidence rates the number of (new) cases (numerator) were divided by the population at risk (denominator). The population at risk was defined as the exact number of person-years lived by this child population at each age. This approach (estimating the exact number of person-years lived instead of number of persons) is appropriate for use in dynamic populations in which changes may occur, for example through births, deaths, or migrations. By using person-years lived, later entries (enlistment) or earlier departures are taken into account. ${ }^{18,19}$ Consequently, prevalence was defined as the number of children with a prescription of asthma medication per 1,000 person-years lived. Incidence was likewise expressed per 1,000 person-years lived. The medication history of the children was followed back to 1994 to consider whether the first prescription occurred during the study period or earlier. Children with time intervals between prescriptions larger than one year were considered as incident cases more than once. For those children aged 1 year and older who became enlisted during the study period, a period of half a year was taken to assess whether asthma medication was prescribed for the first time. The age pattern of asthma medication use in childhood was assessed for the population of incident users during the study period. Indications of asthma (ICPC-code R96) were examined per $n^{\text {th }}$ prescription for each patient to determine whether such an indication was recorded more frequently with increased number of asthma medication prescriptions.

\section{- Longitudinal analysis}

We assessed the predictive value of a first prescription of asthma medication in the group of children who had their first prescription at the ages of 0 to 3 during the study period. 
The predictive value was defined as the probability of continuing treatment beyond the age of 6 . The (dis)continuation in time was shown with Kaplan-Meier survival curves, where cumulative survival was defined here as the continuation of asthma medication. The duration of medication use was estimated on the basis of the recorded data on dosage and amount or volume prescribed. Because no data on actual medication use were available, in this analysis we assumed continuing use of medication between every set of consecutive prescription days, without taking into account possible intervals with temporary discontinuation.

\section{- Retrospective case-control analysis}

Children from the birth cohorts 1995-1998 were selected for the retrospective analysis if they had started using asthma medication prior to their 6th birthday and had reached the age of 6 during the study period. Children enlisted at 6 months of age or older or children departed before their 6th birthday were excluded from the analysis. The study population was divided into a group who had had a prescription of asthma medication beyond their 6th birthday (cases) and a group without such a prescription (controls). Univariate logistic regression analysis was used to compare these two groups with respect to age at first prescription, sex, indication at first prescription, antibiotic use, presence of eczema, and type of asthma medication.

\section{Results}

\section{Study population}

During the study period (1998-2005), the database covered a total population of approximately 43,000 patients. The population of children aged 0 to 9 years amounted to 7,372 of whom 1047 had been prescribed asthma medication during the study period. The amount of person-years lived in the age group 0-9 years during the study period was 3,339, being $11 \%$

Figure 1. Prevalence and incidence of prescriptions of asthma medication (per 1,000 person-years lived), RNG population (age 0-9 years), study period 1998-2005.

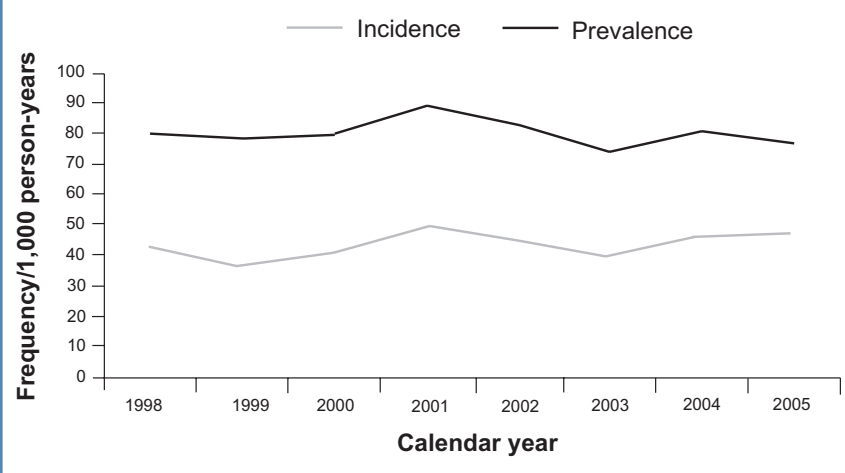

of the total amount of person-years lived in the total population $(29,458)$. The yearly number of person-years lived in this age group ranged from 3,271 to 3,407, with a near uniform distribution across the ages.

\section{Cross-sectional analysis}

Prevalence and incidence of asthma medication prescriptions in children

The yearly prevalence of prescribing asthma medication ranged from 74 to 89 children per 1,000 person-years, and the incidence ranged from 37 to 49 children per 1,000 person-years (Figure 1). Both occurrence measures temporarily increased around the year 2001, but did not show sharp fluctuations or a clear trend. Table 1 shows that, as expected, the most commonly prescribed asthma medication were $\beta_{2}$-agonists. The yearly prevalence rate of both $\beta_{2}$-agonist and ICS prescriptions varied between 19 and 34 per 1,000 person-years during the study period. Low prevalences for both long-acting $\beta_{2}$-agonist prescriptions $(0.3$ to 2.7 per 1,000 person-years) and combination therapy (long-acting $\beta_{2}$-agonists and ICS) prescriptions were found (0 to 0.9 per 1,000 person-years). Yearly prevalence rates between 12 and 20 per 1,000 person-years were found for prescriptions for ICS monotherapy. Table 2 shows that there was a strong tendency to start early with asthma medication, since the incidences were highest for children aged 0 or 1 , respectively 115.4 and 62.9 . The probability that a first prescription was given to infants before their first birthday was $29 \%$, and this rose to more than $50 \%$ in children aged $<3$ years.

Table 1. Prevalence of prescriptions for different types of asthma medication (per 1,000 person-years lived), RNG population (age 0-9 years), study period 1998-2005.

$$
\text { Calendar } \beta_{2} \text {-agonist } \quad \beta_{2} \text {-agonist and ICS* } \quad \text { ICS }
$$
year monotherapy total LABA combination monotherapy

\begin{tabular}{llllll}
\hline 1998 & 42 & 24 & 2.7 & 0 & 12 \\
\hline 1999 & 31 & 31 & 2.7 & 0 & 15 \\
\hline 2000 & 35 & 30 & 2.4 & 0.3 & 15 \\
\hline 2001 & 35 & 34 & 2.1 & 0.6 & 20 \\
\hline 2002 & 31 & 34 & 1.2 & 0.9 & 17 \\
\hline 2003 & 29 & 26 & 1.8 & 0.9 & 19 \\
\hline 2004 & 34 & 27 & 0.9 & 0.6 & 20 \\
\hline 2005 & 38 & 19 & 0.3 & 0.6 & 19 \\
\hline
\end{tabular}

ICS, inhaled corticosteroids; ${ }^{*} \beta_{2}$-agonist as well as ICS; total indicates prevalences of prescriptions of $\beta_{2}$-agonists as well as ICS prescriptions; LABA indicates prevalences of long-acting $\beta_{2}$-agonists added to ICS prescriptions; combination indicates prevalences of prescriptions of combination therapy (long-acting $\beta_{2}$-agonist and ICS in one device). 


\begin{tabular}{llll}
$\begin{array}{l}\text { Table 2. Incidence of prescribing asthma medication (per } \\
\text { 1,000 person-years lived), RNG population (age 0-9 } \\
\text { years), study period } \\
\text { 1998-2005. }\end{array}$ \\
$\begin{array}{l}\text { Age } x \\
\text { (yrs) }\end{array}$ & Incidence & $\begin{array}{c}\text { Yearly incidence } \\
\text { range } \\
1998-2005\end{array}$ & $\begin{array}{c}\text { Cumulative } \\
\text { probability of } \\
\text { starting before age } x\end{array}$ \\
\hline 0 & 115.4 & $99.0-132.1$ & \\
\hline 1 & 62.9 & $39.3-85.0$ & 0.29 \\
\hline 2 & 44.2 & $35.6-52.1$ & 0.44 \\
\hline 3 & 40.2 & $30.8-53.8$ & 0.54 \\
\hline 4 & 38.3 & $22.6-67.7$ & 0.63 \\
\hline 5 & 33.8 & $22.3-44.0$ & 0.72 \\
\hline 6 & 27.4 & $19.9-32.7$ & 0.79 \\
\hline 7 & 22.7 & $10.1-57.7$ & 0.85 \\
\hline 8 & 21.6 & $6.4-52.3$ & 0.90 \\
\hline 9 & 20.0 & $9.6-26.6$ & 0.95 \\
\hline 10 & & & 1.00 \\
\hline $0-9$ & 43.4 & $37.1-49.3$ & \\
\hline & & & \\
\hline
\end{tabular}

\section{Indications}

Asthma was not the only diagnostic indication when asthma medication was prescribed. At the start of the treatment other indications such as coughing and respiratory infections or symptoms were recorded frequently. When treatment with these drugs continued for a longer period of time, asthma remained as the single most important indication (Figure 2). An asthma diagnosis was registered in $40 \%$ of the children with a first prescription and in $70 \%$ of the children with six or more prescriptions.

\section{Longitudinal analysis}

Age at first prescription and continuation of asthma medication prescriptions in children

Continuation of asthma medication in children with a first prescription at the ages of $0,1,2$ or 3, respectively, are shown in Figure 3. High probabilities of discontinuation after the first prescription were found in all age groups. The percentage of children with only one single prescription was around $40 \%$ for children aged $\leq 1$ year, but this decreased to $30 \%$ or less for children aged $>2$ years. The percentage of children still receiving asthma medication prescriptions beyond the age of 6 was much higher for children starting treatment at ages 2 or 3 years as compared to children who had their first prescription at age $\leq 1$ year $(35-40 \%$ and $10-15 \%$, respectively).

\section{Retrospective case-control analysis}

Predictors of continuation

Data on 178 children (who had a complete medical history and at least one prescription before the age of 6), were
Figure 2. Indications registered with the prescription of asthma medication, by $n$-th prescription per patient, all prescriptions up to the 10th prescription rank, RNG population (age 0-9 years), 1998-2005.

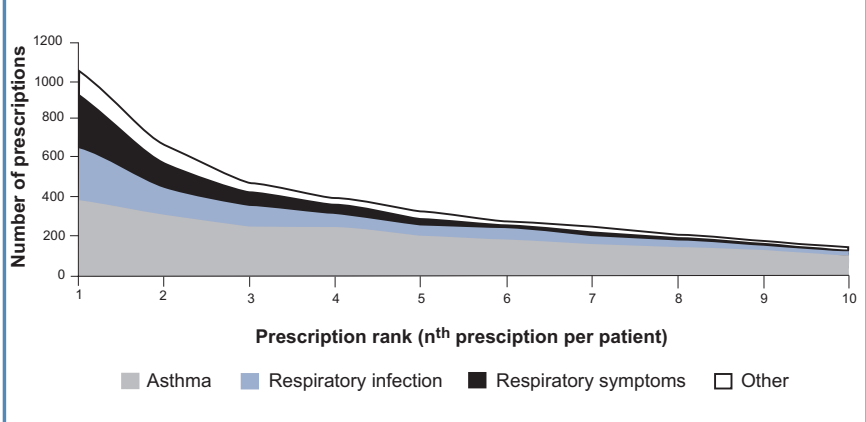

Figure 3. Kaplan-Meier curves of continuation of asthma-medication beyond the age of 6 , by age of first prescription, RNG child population of incident users, 1998-2005.

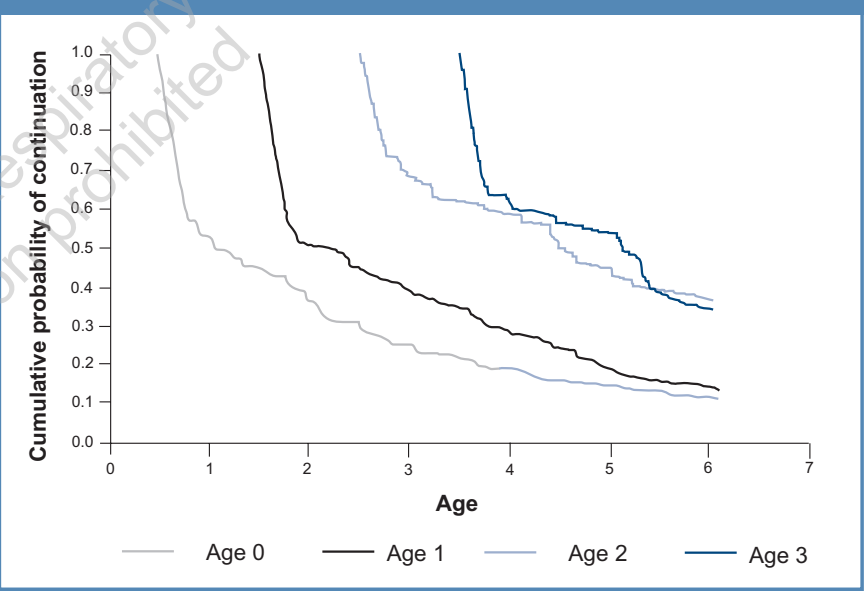

analysed retrospectively. The results are shown in Table 3. Age at first prescription emerged as an important discriminating factor, demonstrating a greater likelihood of continuation of asthma medication prescriptions in children starting treatment at age 2 or 3 as compared to children who started treatment at a younger age $(\leq 1)$. The type of asthma medication prescription was also found to be predictive for continuation; children who were prescribed both $\beta_{2}$-agonist and ICS were more likely to continue, as compared to children who were prescribed $\beta_{2}$-agonist monotherapy. Although not reaching statistical significance, there was a tendency $(p=.06)$ that the indication registered at the first asthma medication prescription was prognostic for continuation of asthma medication beyond the age of 6 . The OR of 1.84 suggested a greater likelihood of continuation with asthma medication prescriptions in children with an asthma diagnosis registered at first prescription as compared to children with other 
S Schokker et al.

Table 3. Continuation of asthma medication beyond the age of 6, parameter estimates of univariate logistic regression models, RNG population of incident users, cohort 1995-1998.

\begin{tabular}{|c|c|c|}
\hline Sex & $\begin{array}{l}\text { female (ref.) } \\
\text { male }\end{array}$ & $1.33(.70 ; 2.53)$ \\
\hline Age at first prescription & $\begin{array}{l}0-1 \text { (ref.) } \\
2-3 \\
4-5\end{array}$ & $\begin{array}{ll}2.06^{*} & (1.01 ; 4.19) \\
1.34 & (.61 ; 2.94)\end{array}$ \\
\hline Indication registered at first asthma medication prescription & $\begin{array}{l}\text { other than asthma (ref.) } \\
\text { asthma }\end{array}$ & $1.84 \quad(.96 ; 3.50)$ \\
\hline Antibiotics & $\begin{array}{l}\text { no prescription (ref.) } \\
\text { prescription in medical history }\end{array}$ & $2.63 \quad(.93 ; 7.42)$ \\
\hline
\end{tabular}

indications. Prescribing antibiotics was not an important discriminating variable in the logistic regression model, although it is important to bear in mind that prescriptions of antibiotics were extremely common in early life. Gender and the presence of eczema in the medical history also had no additional effect in the model.

\section{Discussion}

This study shows that the prescribing of asthma medication for children in primary care occurs frequently and is often accompanied by indications other than asthma. Moreover, continuation of these prescriptions from preschool into school-age is low. Age at first prescription and type of asthma medication appear to be predictors for continuation; there was a higher likelihood of continuation in children with a first prescription at the age of 2 or 3 years compared to children starting treatment at $\leq 1$ year, and a higher likelihood of continuation in children with prescriptions for both $\beta_{2}$ agonists and ICS as compared to children with prescriptions for $\beta_{2}$-agonist monotherapy.

These findings concur with prospective birth cohort studies which have shown that, in the majority of children with symptoms suggestive of asthma in early life, symptoms are transient and may not require asthma medication at school age. ${ }^{1}$ In clinical practice, therefore, it is important to inform parents of children receiving a prescription about the uncertainty of a diagnosis of asthma in early life; it might be appropriate to explain that many children, particularly those presenting in infancy, will outgrow their symptoms and that medication can often be discontinued in due time.

Our results also indicate that the asthma medication prescribed for our study population seems to be in accordance with guidelines (i.e. a stepwise approach) ${ }^{6-8}$ Surprisingly (yet consistent with a study by Zuidgeest et al. ${ }^{20}$ ), our study revealed a group of children who were receiving ICS monotherapy without a prescription for a $\beta_{2}$-agonist in that same year, which might suggest overtreatment in these children. However, an alternative explanation might be that the $\beta_{2}$-agonists dispensed in the previous year were used for children who only need reliever medication occasionally (i.e. children with well-controlled asthma, which might actually be the result of good maintenance therapy).

The persistence of asthma medication in preschool children has been studied recently. ${ }^{21}$ In 165 children who used asthma medication before the age of one - as identified from the PIAMA (Prevention and Incidence of Asthma and Mite Allergy) birth cohort - a low continuation of asthma medication was revealed; only $10.3 \%$ of the children in this study continued asthma medication for three years. Another finding from this study by Zuidgeest et al. ${ }^{21}$ was that continuation was more likely in children with doctordiagnosed asthma or those who were prescribed ICS in the first year of life. Although the age of children included in our study (0-9 years) was different from the study population included by Zuidgeest et al., the findings are comparable. We also found a borderline significance for the prognostic value of the indication registered at the first prescription; the likelihood of continuation with asthma medication is almost twofold higher in children who have an asthma diagnosis at first prescription as compared to those without an asthma diagnosis (e.g. children with infection or symptom-based diagnoses). Furthermore, in our study children with 
prescriptions for both $\beta_{2}$-agonists and ICS had a higher likelihood of continuing with asthma medication as compared to children with $\beta_{2}$-agonist monotherapy. However, it is important to emphasise the role of disease severity when interpreting these findings (with regard to the prognostic value of a diagnosis of asthma at the first prescription or prescriptions of both $\beta_{2}$-agonist and ICS); a diagnosis of asthma will be more likely in children with persistent severe symptoms, in whom maintenance therapy with ICS is recommended.

Furthermore, we have found a higher likelihood of continuation with medication beyond the age of 6 years in children who started treatment at 2 or 3 years of age as compared to children who had started at age 1 year or before. This might be related to the assumption that the natural history of respiratory symptoms is dependent on the age at first presentation - i.e., the earlier the onset, the better the prognosis. Based on cohort studies, a breaking point at 2 years of age is considered appropriate, with the majority of those presenting symptoms before this age becoming asymptomatic by mid-childhood. ${ }^{22}$

Consistent with another Dutch study in primary care, ${ }^{20}$ we found that less than $40 \%$ of all children with a first prescription of asthma medication had a registered doctor diagnosis of asthma. The incremental change in the likelihood of having a doctor diagnosis of asthma with each repeated prescription of asthma medication found in our study (Figure 2 ) is also in line with the findings of Zuidgeest et al. However, both studies reveal that, even in children with prolonged use of asthma medication (and in children older than 6 years of age), a large proportion of children receive asthma medication without having a doctor diagnosis of asthma. It is becoming increasingly obvious that many children are over-treated with asthma medication - especially since the majority of young children will have viral-associated wheeze instead of 'real' asthma. On the other hand, we need to remain aware of asthma under-diagnosis and under-treatment. The crucial issue remains; it is difficult to diagnose asthma in children accurately.

Results of a birth cohort study using data from a general practice-based system (the PREVASC trial) indicated that PCPs' diagnosis of asthma at age 0-3 years is not accurate. In this study, only $19 \%$ of children with recurrent wheezing diagnosed as asthma in the first three years of life, actually had asthma in adolescence. At 4-6 years of age, a correct diagnosis appeared to be less problematic for the PCP, since $80 \%$ of the children given an asthma diagnosis in this age group had asthma in adolescence. ${ }^{5}$ However, the diagnosis for the children in our study who received no repeat asthma prescription after the age of 6 remains uncertain. Although it is likely that these children have minor or few symptoms (since no renewals of prescriptions were required), they may be in remission and could require asthma medication later in life.

The strength of this study is that data were obtained from a very accurate general practice-based registration system in which both prescriptions and indications for prescriptions are registered longitudinally. ${ }^{23}$ In the Netherlands, the primary care setting provides free consultations and free medication without limitations. Furthermore, all patients are registered to, and therefore visit, only one primary care practice. This gives PCPs in the Netherlands a unique opportunity to follow-up the majority of patients for long periods of time.

A limitation of this study is the relatively small sample size - in particular, the sample size for assessing prognostic factors. Furthermore, the data were derived from a regional registration system; however, since our results are supported by other studies, it is unlikely that the regional nature of our data has hampered the generalisability of the results. Finally, we acknowledge that patient-based data (e.g. actual use of the medication, severity of symptoms) as well as objective lung function data could have enriched this study.

\section{Conclusion}

This study shows that the prescribing of asthma medication in children in primary care is common. However, this does not necessarily lead to a (final) diagnosis of asthma and discontinuation of these prescriptions is likely. Our results reinforce the diagnostic difficulties facing physicians when dealing with childhood asthma. It is important to realise that children with symptoms suggestive of asthma often outgrow their disease. Only 10 to $40 \%$ of children continued medication after the age of 6 , a factor which indicates a persistent asthma diagnosis. PCPs should be aware of this and should restrict or at least review frequently the prescribing of asthma medication in young children in order to avoid overtreatment.

\section{Acknowledgement}

We thank Dr Juliet M. Foster for her comments on the manuscript.

\section{Conflict of interest}

None to declare.

\section{References}

1. Martinez FD, Wright AL, Taussig LM, Holberg CJ, Halonen M, Morgan WJ. Asthma and wheezing in the first six years of life. The Group Health Medical Associates. N Engl J Med 1995; 332:133-8. http://dx.doi.org/ 10.1056/NEJM199501193320301

2. Bush A. Diagnosis of asthma in children under five. Prim Care Resp J 2007; 16:7-15. http://dx.doi.org/10.3132/pcrj.2007.00001

3. Castro-Rodriguez JA, Holberg CJ, Wright AL, Martinez FD. A clinical index to define risk of asthma in young children with recurrent wheezing. Am J Respir Crit Care Med 2000;162:1403-06.

4. Eysink PE, ter Riet $G$, Aalberse RC, et al. Accuracy of specific lgE in the prediction of asthma: development of a scoring formula for general practice. $\mathrm{Br}$ J Gen Pract 2005;55:125-31. 
5. Schonberger $\mathrm{H}$, van Schayck O, Muris J, et al. Towards improving the accuracy of diagnosing asthma in early childhood. Eur J Gen Pract 2004;10:138-45, 151.

6. Bindels PJ, Grol MH, Ponsioen BP, Salome PL, Wiersma T, Goudswaard AN. Summary of the practice guideline 'Asthma in children' (second revision) from the Dutch College of General Practitioners. Ned Tijdschr Geneeskd 2008; 152:550-5

7. Duiverman EJ, Brackel HJ, Merkus PJ, Rottier BL, Brand PL. Guideline 'Treating asthma in children' for pediatric pulmonologists (2nd revised edition). II. Medical treatment. Ned Tijdschr Geneeskd 2003;147:1909-13.

8. van der Molen T, Ostrem A, Stallberg B, Ostergaard MS, Singh RB. International Primary Care Respiratory Group (IPCRG) Guidelines: management of asthma. Prim Care Resp J 2006;15:35-47. http://dx.doi.org/10.1016/j.pcrj.2005.11.001

9. Guilbert TW, Morgan WJ, Zeiger RS, et al. Long-term inhaled corticosteroids in preschool children at high risk for asthma. N Engl J Med 2006;354:1985-97. http://dx.doi.org/10.1056/NEJMoa051378

10. Bisgaard $H$, Hermansen MN, Loland L, Halkjaer LB, Buchvald F. Intermittent inhaled corticosteroids in infants with episodic wheezing. N Engl J Med 2006; 354:1998-2005. http://dx.doi.org/10.1056/NEJMoa054692

11. Murray CS, Woodcock A, Langley SJ, Morris J, Custovic A. Secondary prevention of asthma by the use of Inhaled Fluticasone propionate in Wheezy INfants (IFWIN): double-blind, randomised, controlled study. Lancet 2006; 368:754-62. http://dx.doi.org/10.1016/\$0140-6736(06)69285-4

12. Bisgaard H, Gillies J, Groenewald M, Maden C. The effect of inhaled fluticasone propionate in the treatment of young asthmatic children: a dose comparison study. Am J Respir Crit Care Med 1999;160:126-31.

13. Pao CS, McKenzie SA. Randomized Controlled Trial of Fluticasone in Preschool Children with Intermittent Wheeze. Am J Respir Crit Care Med 2002;166:945-
9. http://dx.doi.org/10.1164/rccm.200203-2650C

14. Baxter-Jones ADG, Helms PJ. Early introduction of inhaled steroids in wheezing children presenting in primary care. A pilot study. Clin Exp Allergy 2000; 30:1618-26. http://dx.doi.org/10.1046/j.1365-2222.2000.00941.x

15. Schokker S, Kooi EM, de Vries TW, et al. Inhaled corticosteroids for recurrent respiratory symptoms in preschool children in general practice: Randomized controlled trial. Pulm Pharmacol Ther 2008;21:88-97. http://dx.doi.org/10.1016/j.pupt.2006.12.007

16. Lamberts $\mathrm{H}$, Wood M. International classification of primary care. Oxford: Oxford University Press; 1987.

17. WHO collaborating centre for drug statistics methodology. ATC Index with DDS. 1999. Norway, WHO-report.

18. Gordis L. Epidemiology. 4th ed. Philadelphia: Elsevier-Saunders; 2008.

19. Last JM. A dictionary of Epidemiology. 4th ed. New York: Oxford Medical Publications; 2001

20. Zuidgeest MG, van DL, Smit HA, et al. Prescription of respiratory medication without an asthma diagnosis in children: a population based study. BMC Health Serv Res 2008;8:16. http://dx.doi.org/10.1186/1472-6963-8-16

21. Zuidgeest MG, Smit HA, Bracke M, et al. Persistence of asthma medication use in preschool children. Respir Med 2008;102:1446-51. http://dx.doi.org/10.1016/j.rmed.2008.04.003

22. Helms PJ, Amre D. Prognosis of wheezing and asthma presenting in early childhood. Breathe 2004;1:131-7.

23. van der Veen WJ, Meyboom-de Jong B. Age and gender. In: Jones R, Britten N, Culpepper L, Gass DA, Grol R, Mant D et al., editors. Oxford Textbook of Primary Medical Care. Oxford University Press, Oxford; 2004. 153-160.

\title{
COMMENTARY
}

\section{Re: Schokker et al. Prim Care Resp 12010;19(1):28-34 Prescribing of asthma medication in primary care for children aged under 10}

\author{
*lain Smalla \\ a Peterhead Health Centre, Links Terrace, Peterhead, Aberdeenshire, Scotland, UK; Honorary Lecturer, Centre for Academic Primary Care, \\ University of Aberdeen, Scotland, UK; Chair, PCRS-UK Executive Commitee
}

Childhood respiratory illnesses are common. For example, it has been estimated that at least $50 \%$ of children wheeze for some reason at some point in their childhood. ${ }^{1}$ In addition, it is often quite difficult for the clinician treating a child to establish the pathology generating a child's illness and then to decide on treatment and to predict response. Furthermore, there is often inconsistent (or indeed insufficient) evidence to support the use of commonly prescribed treatments, leaving primary care clinicians to make decisions based on a combination of experience, peer opinion, and anecdote. ${ }^{2}$ However, in this issue of the PCRJ, Schokker et al. ${ }^{3}$ have analysed the way in which primary care doctors in Holland prescribe asthma medicines such as short-acting $\beta_{2}$-agonists (SABA), long-acting $\beta_{2}$-agonists, (LABA), and inhaled corticosteroids (ICS), and in so doing have shed some light on this complex issue.

Guidelines tend to oversimplify prescribing advice for health professionals when treating patients with a diagnosis of asthma, or (if there is no confirmed diagnosis) when trying a trial of therapy as a diagnostic tool. ${ }^{4,5}$ However, the patterns of prescribing behaviour described in this paper are very different, and there are lessons to be learnt regarding the implementation of asthma guidelines. The researchers describe a number of important aspects related to the pharmacotherapeutic management of children with

\footnotetext{
* Corresponding author: Dr lain Small, Peterhead Health Centre, Links Terrace, Peterhead, Aberdeenshire, Scotland, UK.

Tel: +44 (0)1779 474841 Fax: +44 (0)1779 482571 E-mail: iain.small@nhs.net
} 